\title{
Electroencephalography and phenytoin toxicity in mentally retarded epileptic patients
}

\author{
M. I I V A N A I N E N, M. V I U K A R I, A. - M. S E P P ̈̈ L ̈̈ I N N, \\ A N D E. - P. HE L L E \\ From the Department of Neurology, University of Helsinki, Helsinki, and Research Department, \\ Rinnekoti Institution for the Mentally Retarded, Espoo, Finland
}

SUMMARY There were significantly more diffuse and focal electroencephalographic abnormalities in 127 mentally retarded epileptic patients treated with phenytoin than in 68 epileptics without phenytoin. Phenytoin intoxication made the difference still more pronounced. Monitoring drug levels and electroencephalograms appears to be the method of choice for ensuring safe and effective medication in intractable epilepsy.

Epilepsy is compatible with many types of electroencephalographic abnormalities. Abnormal electroencephalograms (EEGs) are also recorded in mental retardation, where they may reveal the location, type, and severity of the central affection (Gibbs and Gibbs, 1965; Iivanainen, 1974). In neuropharmacology, the EEG remains the most sensitive and recordable index of brain function in intact man; changes in frequency, power, and amplitude of waking and sleeping EEGs are the principal indices studied (Fink, 1969).

Electroencephalography has commonly been used in epilepsy to monitor the therapeutic response. In patients receiving phenytoin, the EEG is thought to be modified only when dosages of this drug approach the toxic range (Roseman, 1961). Electroencephalographic alterations then vary from slowing in the alpha frequency range in mild cases to marked delta activity in severe ones.

Diffuse EEG abnormalities with 4 to $7 \mathrm{~Hz}$ slow activity but not lateralised were recorded in about half of a group of epileptic patients all of whom showed clinical signs of phenytoin intoxication after oral administration of the drug (Jensen and Grynderup, 1966). Moreover, an increased frequency of epileptic seizures has been reported to correlate positively with increases in the serum phenytoin level of, on average, $12 \mu \mathrm{g} / \mathrm{ml}$ or more (Stensrud and Palmer, 1964).

Address for correspondence and reprint requests: $\mathrm{Dr}$ M. Iivanainen, National Institutes of Health, National Institute of Neurological and Communicative Disorders and Stroke, Bldg 36, Rm 5D-06, Bethesda, Maryland 20014, USA.

Accepted 10 October 1977
This study examines the relationship between EEG abnormalities and the serum concentration of phenytoin in a group of mentally retarded epileptics whom we have earlier examined exhaustively (Viukari, 1970; Iivanainen, 1974). We reported on the pneumoencephalographic findings, especially those indicative of cerebellar atrophy, as well as on the serum concentrations of phenytoin in these same patients (Iivanainen et al., 1977). The preliminary results of the present study have been reported previously (Iivanainen and Viukari, 1977).

\section{Patients and methods}

Of the 338 mentally retarded patients studied neuroradiologically and reported previously (Iivanainen, 1974), 210 had epilepsy. Of these 210 epileptics, 131 had been treated with phenytoin (see details in Iivanainen et al., 1977), and 127 (mean age $16.3 \pm 7.3$ years) were submitted to EEG. Sixty-eight epileptic subjects (mean age $17.4 \pm 8.5$ years) who had been treated without phenytoin were submitted to EEG and served as a reference group. All patients had been residents of the Rinnekoti Institution for the Mentally Retarded for several years. Of the phenytoin-treated epileptic patients, 37 had a focal, 41 a centrencephalic, and 49 a miscellaneous type of epilepsy. The corresponding figures for the reference group were 9,17 , and 42 , respectively. In more than half, mental retardation was profound and of prenatal origin. More than $90 \%$ had an abnormal pneumoencephalogram, with brain stem or cerebellar 
atrophy, or both, detectable in $28 \%$. Comparison of other clinical data of the phenytoin-treated and nonphenytoin-treated patients showed no significant differences (Table 1).

Table 1 Clinical data on 127 mentally retarded epileptics treated with and 68 treated without phenytoin

\begin{tabular}{|c|c|c|c|c|}
\hline \multirow[b]{2}{*}{ Data } & \multicolumn{2}{|c|}{ Phenytoin } & \multicolumn{2}{|c|}{ Nonphenytoin } \\
\hline & Number & $\%$ & Number & $\%$ \\
\hline Males & 74 & 58 & 36 & 53 \\
\hline Females & 53 & 42 & 32 & 47 \\
\hline \multicolumn{5}{|l|}{ Upper motor neurone } \\
\hline involvement & 71 & 56 & 29 & 43 \\
\hline \multicolumn{5}{|l|}{ Degree of mental retardation } \\
\hline Borderline & 2 & 2 & 1 & 1 \\
\hline Mild & 5 & 4 & 4 & 6 \\
\hline Moderate & 15 & 12 & 7 & 10 \\
\hline Severe & 26 & 20 & 13 & 19 \\
\hline Profound & 78 & 61 & 43 & 63 \\
\hline Unspecified & 1 & 1 & - & - \\
\hline \multicolumn{5}{|l|}{ Origin of mental retardation } \\
\hline Prenatal & 45 & 35 & 25 & 37 \\
\hline Perinatal & 24 & 19 & 12 & 18 \\
\hline Postnatal & 29 & 23 & 9 & 13 \\
\hline More than one category & 6 & 5 & 6 & 9 \\
\hline Unknown & 23 & 18 & 16 & 24 \\
\hline \multicolumn{5}{|l|}{ Abnormal } \\
\hline pneumoencephalogram & 120 & 94 & 62 & 91 \\
\hline Ventricular enlargement & 91 & 72 & 43 & 63 \\
\hline Brain stem and/or & & & & \\
\hline cerebellar atrophy & 35 & 28 & 20 & 29 \\
\hline
\end{tabular}

The oral dosage of phenytoin averaged $5.6 \pm 2.4$ $\mathrm{mg} / \mathrm{kg}$ body weight. The serum concentration of this drug was assayed with an ultraviolet absorption procedure (for details see Viukari, 1970) in 84 patients receiving long-term phenytoin therapy and in most cases suspected of having phenytoin intoxication. These assays showed their mean serum concentration to be $23.3 \pm 13.8 \mu \mathrm{g} / \mathrm{ml}$. Phenytoin intoxication was diagnosed in $70(55 \%)$ of the 127 patients treated with this drug: (1) from the typical clinical signs of such toxicity, which remitted at least partly when the dosage of phenytoin was reduced, and (2) from a serum phenytoin level $25-30 \mu \mathrm{g} / \mathrm{ml}$ or higher.

Phenytoin was the only antiepileptic drug given to 21 patients. Other drugs were administered as follows: phenobarbitone to $53(40 \%)$ patients, primidone to $27(21 \%)$, carbamazepine to seven $(5 \%)$, sulthiame to $7(5 \%)$, other anticonvulsants to six $(5 \%)$, phenothiazines to $24(18 \%)$, lynoestrenol to $12(9 \%)$, benzodiazepines to $10(8 \%)$, isoniazid to eight $(6 \%)$, methylphenidate to three $(2 \%)$, tetracyclines to three $(2 \%)$, and other drugs to $14(11 \%)$.

Electroencephalographic changes were not used as a criterion of severity of epilepsy nor as an aid for monitoring anticonvulsant treatment. At that time we tried to substitute phenytoin for sedative anticonvulsant drugs because the latter were thought to cause impairment of psychomotor functions of the mentally retarded epileptics. Thus, the severity of epilepsy was not a crucial factor in the decision to treat with phenytoin or not, but it must have contributed to the therapeutic efforts (using combinations of drugs and pushing the dosage higher).

\section{ELECTROENCEPHALOGRAPHIC RECORDINGS}

Recordings of the EEG (waking and asleep) were taken from 127 of the epileptic patients treated with phenytoin. The other four patients in this group could not be studied because of restlessness and are omitted from the results. Anxious patients received chloral hydrate or pentobarbitone sodium before recording the EEG. All EEGs were registered with an eight-channel Kaiser electroencephalograph, and were interpreted according to conventional methods and classified by the system of Dumermuth (1965). More than one EEG was available from several patients, and the analysis of our results takes into account the relevant findings in all EEGs. Antiepileptic medication was not discontinued before recordings. Electroencephalographic recordings and serum phenytoin determinations took place in most cases within four weeks of each other while the dosage of phenytoin remained unchanged. Electroencephalographic readings were made in 68 patients in the reference group in the same way as in the test group. The remaining 11 patients in the reference group could not be studied electroencephalographically because of restlessness.

\section{STATISTICAL TREATMENT}

The results were analysed statistically at the Computing Centre, University of Helsinki. Correlations between EEG findings and other clinical variables, including serum phenytoin levels, were computed with standard programs. Significance of correlations was tested between continuous variables with Student's $t$ test and a correlation matrix, and between discrete variables with the $\chi^{2}$ test.

\section{Results}

Abnormalities in the EEGs of all patients are summarised in Tables 2 and 3. Compared with the reference group, phenytoin-treated epileptic patients had significantly more diffuse slow wave abnormalities, abundant focal spikes and sharp waves, and generalised irregular spikes and waves (Table 2). The statistical significance of these findings was still greater when epileptics intoxicated with phenytoin were compared with this 
Table 2 Electroencephalographic abnormalities in 127 mentally retarded epileptics treated with and 68 treated without phenytoin

\begin{tabular}{|c|c|c|c|c|}
\hline \multirow{2}{*}{$\begin{array}{l}\text { Electroencephalographic } \\
\text { abnormality }\end{array}$} & \multicolumn{2}{|c|}{ Phenytoin } & \multicolumn{2}{|c|}{ Nonphenytoin } \\
\hline & Number & $\%$ & Number & $\%$ \\
\hline \multicolumn{5}{|l|}{$\begin{array}{l}\text { Diffuse slow wave } \\
\text { abnormalities }\end{array}$} \\
\hline slight & $26^{*}$ & 20 & 23 & 34 \\
\hline moderately severe & 70 & 54 & 35 & 51 \\
\hline severe & $22 \dagger$ & 17 & 2 & 3 \\
\hline Abnormal $\beta$ activity & 12 & 9 & 7 & 10 \\
\hline Asymmetry or depression of & & & & \\
\hline Focal slow wave abnormalities & 19 & 15 & 5 & 7 \\
\hline $\begin{array}{l}\text { slight } \\
\text { moderately severe and }\end{array}$ & 11 & 8 & 5 & 7 \\
\hline severe & 15 & 12 & 3 & 4 \\
\hline $\begin{array}{l}\text { Paroxysmal slow activity } \\
\text { Focal spikes and sharp waves }\end{array}$ & 28 & 22 & 11 & 16 \\
\hline $\begin{array}{l}\text { a few } \\
\text { abundant }\end{array}$ & $\begin{array}{l}14 \\
27+\end{array}$ & $\begin{array}{l}11 \\
21\end{array}$ & $\begin{array}{l}8 \\
3\end{array}$ & $\begin{array}{r}12 \\
4\end{array}$ \\
\hline $\begin{array}{l}\text { Generalised irregular } \\
\text { spikes and waves } \\
\text { Rhythmical } 2-2.5 \text { per }\end{array}$ & $37 \S$ & 29 & 8 & 12 \\
\hline second spikes and waves & 11 & 8 & 2 & 3 \\
\hline
\end{tabular}

reference population (Table 3).

Either paroxysmal or slow focal EEG abnormalities were recorded in 67 phenytoin-treated and in only 19 nonphenytoin-treated patients $\left(\chi^{2}=9.8\right.$; $P<0.01)$. Occipital EEG abnormalities were more frequent in epileptic patients intoxicated with phenytoin than in either those not so intoxicated $\left(10 / 70\right.$ versus $\left.0 / 57 ; \chi^{2}=8.8 ; \mathrm{P}<0.01\right)$ or in epileptics not treated with phenytoin $(10 / 70)$ versus $1 / 57$ $\left.\chi^{2}=7.7 ; \mathrm{P}<0.01\right)$. Focal EEG abnormalities, however, were most frequently localised in the temporal region $(20$ patients $(30 \%)$ of the 67 phenytoin-treated patients with focal EEG abnormalities).

The serum phenytoin concentration $(34.9 \pm 8.1$ $\mu \mathrm{g} / \mathrm{ml}$ ) of patients with moderately severe focal slow wave abnormalities was significantly higher than that of patients (1) with slight focal slow wave abnormalities $(19.6 \pm 11.5 \mu \mathrm{g} / \mathrm{ml} ; \mathrm{P}<0.01)$, (2) with asymmetry or depression of background activity $(21.4 \pm 9.3 \mu \mathrm{g} / \mathrm{ml} ; \mathrm{P}<0.001)$, or (3) with no local nonspecific EEG abnormalities (23.0 \pm $15.1 \mu \mathrm{g} / \mathrm{ml} ; \mathrm{P}<0.05)$. The mean serum phenytoin level of patients with multiple or fluctuating focal EEG abnormalities $(31.7 \pm 18.0 \mu \mathrm{g} / \mathrm{ml})$ was higher than that of patients who had a focal EEG abnormality in a constant site, and significantly higher than that of patients with no focal EEG abnormalities $(21.6 \pm 12.9 \mu \mathrm{g} / \mathrm{ml} ; \mathrm{P}<0.05)$.

A consideration of laterality showed that patients with right sided focal EEG abnormalities had the highest mean serum concentration of phenytoin $(29.3 \pm 16.1 \mu \mathrm{g} / \mathrm{ml})$, and that this concentration was significantly higher than that of patients with no focal EEG abnormalities $(21.4 \pm$ $13.2 \mu \mathrm{g} / \mathrm{ml} ; \mathrm{P}<0.05)$. When intoxicated with phenytoin, patients with right sided EEG abnormalities more rapidly lost their ability to walk than did those with left sided abnormalities (10.8 \pm 9.9 versus $48.0 \pm 24.0 \mathrm{mo} ; \mathrm{P}<0.05$ ), an outcome probably attributable to the high serum phenytoin levels in the former.

Table 3 Correlation of electroencephalographic abnormalities in 70 phenytoin-intoxicated mentally retarded epileptics and in 68 mentally retarded epileptics not treated with phenytoin. For comparison. corresponding figures are given in parentheses for the 57 mentally retarded epileptics treated but not intoxicated with phenytoin.

\begin{tabular}{|c|c|c|c|c|c|c|}
\hline \multirow[b]{2}{*}{ Electroencephalographic abnormality } & \multicolumn{2}{|c|}{ Phenytoin-intoxicated } & \multicolumn{2}{|c|}{ Nonphenytoin-treated } & \multicolumn{2}{|c|}{$\begin{array}{l}\text { Phenytoin-treated } \\
\text { but not intoxicated }\end{array}$} \\
\hline & Number & $\%$ & Number & $\%$ & Number & $\%$ \\
\hline \multicolumn{7}{|l|}{ Diffuse slow wave abnormalities } \\
\hline slight & $12^{*}$ & 17 & 23 & 34 & $(14$ & 25) \\
\hline moderately severe & 39 & 56 & 35 & 51 & (31 & 54) \\
\hline severe & $15+$ & 21 & 2 & 3 & $(7$ & 12) \\
\hline Abnormal $\beta$ activity & 7 & 10 & $\overline{7}$ & 10 & ( 5 & 9) \\
\hline \multirow{2}{*}{\multicolumn{7}{|c|}{ Focal slow wave abnormalities }} \\
\hline & & & & & & \\
\hline slight & 5 & 7 & 5 & 7 & $(6$ & 11) \\
\hline moderately severe and severe & $11+$ & 16 & 3 & 4 & ( 4 & 7) \\
\hline Paroxysmal slow activity & 19 & 27 & 11 & 16 & ( 9 & 16) \\
\hline \multicolumn{7}{|l|}{ Focal spikes and sharp waves } \\
\hline a few & 7 & 10 & 8 & 12 & $(7$ & 12) \\
\hline abundant & $17 \S$ & 24 & 3 & 4 & $(10$ & 18) \\
\hline Generalised irregular spikes and waves & $25 \|$ & 36 & 8 & 12 & $(12$ & 21) \\
\hline Rhythmical $2-2.5$ per second spikes and waves & 9ब & 13 & 2 & 3 & $(2$ & 4) \\
\hline
\end{tabular}

${ }_{\mathrm{P}}<0.05\left(x^{2}=5.1\right) ; \nmid \mathrm{P}<0.001\left(x^{2}=10.9\right) ; \ddagger \mathrm{P}<0.05\left(x^{2}=4.8\right) ; \S \mathrm{P}<0.001\left(x^{2}=11.0\right) ; \| \mathrm{P}<0.001\left(x^{2}=10.9\right) ; \uparrow_{\mathrm{P}}<0.05\left(x^{2}=4.6\right)$. 


\section{Discussion}

Correlations between the severity of epilepsy, high serum levels of phenytoin, and EEG abnormalities are difficult to interpret properly. Phenytoin can induce seizures in man, and a high dose of this drug has caused irritability, ataxia, and convulsions in experimental animals (Levy and Fenichel, 1965). In a patient whose epilepsy is drug resistant, a vicious circle can be set up by increasing the dosage of phenytoin, thereby raising the serum concentration to a possibly toxic level, which in turn increases seizures. In a recent study in which the dosage of phenytoin given to 20 chronic epileptics was raised until therapeutic serum concentrations greater than $40 \mu \mathrm{mol} / 1(10 \mu \mathrm{g} / \mathrm{ml})$ had been attained, the frequency of major seizures increased in three patients $(15 \%)$ (Lambie et al., 1976). Unfortunately, EEGs were not recorded in these patients. Roseman (1961) reported that among the last 1000 epileptics that he treated with phenytoin, toxic effects developed in over $45 \%$. There is evidence, therefore, that phenytoin intoxication may be a not infrequent cause of seizures.

Perucca (1976) has drawn attention to the less widely known clinical features of intoxication with antiepileptic drugs, such as psychiatric and behavioural problems, an increased incidence of seizures, and choreoathetoid movements. Of his patients, 80 to $83 \%$ showed the characteristic EEG pattern of such toxicity (slowing of the background rhythms and impaired reactivity to eye opening, which improved after drug withdrawal). Ahmad et al. (1975) have also attributed involuntary movements and EEG changes to phenytoin intoxication. The findings of these authors support the view of Logan and Freeman (1969) that drug toxicity seems to interact with underlying cerebral disease, an observation that agrees well with our experience (Viukari, 1970; Iivanainen et al., 1977).

The German literature also contains several reports of phenytoin toxicity associated with EEG changes (Müller and Müller, 1972), and one report on an infrequent activation of focal abnormalities by phenytoin (Bente, 1975). Moreover, according to Morrell et al. (1959), although phenytoin may bring about improvement in a previously diffuse abnormal EEG, a localised focus of seizure activity will remain. Buchthal et al. (1960) reported that, although the reduction in paroxysmal activity in the EEG with attainment of a phenytoin serum level of $10 \mu \mathrm{g} / \mathrm{ml}$ or more was the general trend, a transient increase in the incidence of paroxysms sometimes occurred. Similar phenomena were reflected in the present cases of phenytoin intoxication.

When mental retardation occurs in combination with epilepsy, the underlying brain lesion is usually more severe, and EEG abnormalities are more frequent and often also more severe than when epilepsy is absent (Gibbs and Gibbs, 1965; Iivanainen, 1974). Compared with the mildly retarded, severely retarded people have a greater frequency of EEG abnormalities and hence also a higher intake of antiepileptic drugs.

Our results show that EEG recording is a valuable method for detecting intoxication in patients receiving antiepileptic drugs. In our experience, when an EEG pattern compatible with phenytoin toxicity prompted the withdrawal of most of such drug therapy, the patient's mental and physical condition sometimes improved dramatically. Remarkably, even seizure frequency was often reduced. As Roseman put it as early as 1961; "the minimal early slowing of the alpha activity seems to act as a titrating endpoint. Once this point is reached, not only has the therapeutic dose been exceeded but toxic symptoms and signs may be expected. Therefore, it is useless to push the dosage higher, particularly if control of seizures has not been effected". Because some patients are extremely susceptible to phenytoin toxicity, monitoring only serum concentrations of the drug is not enough. Severe signs of intoxication have been reported in patients whose serum phenytoin concentration was only $5 \mu \mathrm{mol} / 1(1 \mu \mathrm{g} /$ ml) (Levy and Fenichel, 1965; Ahmad et al., 1975). Furthermore, in toxic combinations of anticonvulsant drugs, even though the serum concentrations of the individual drugs may be within their therapeutic range, EEG examination may reveal encephalopathy.

Dow (1971) has suggested that EEG examination may be of value in assessing the severity of anticonvulsant-induced toxic states with folate deficiency and in monitoring the efficacy of replacement therapy. He reports on a patient receiving primidone in whom the EEG had had generalised continuous theta activity at 4 to $5 \mathrm{~Hz}$ and runs of delta activity down to $1.5 \mathrm{~Hz}$. Reduction in dosage of primidone and treatment with folic acid brought the EEG back to within "normal limits".

Phenytoin encephalopathy is a rare syndrome of diminishing intellectual capacity combined with an increased frequency of seizures, and some diffuse, cerebellar, and even focal neurological signs, which are induced by phenytoin and reversed at least partly when the drug is withdrawn. This syndrome seems to produce EEG abnormalities (McLellan and Swash, 1974) similar to 
those recorded in our patients. Interestingly, phenytoin also slows the conduction velocity of peripheral nerves (Le Quesne et al., 1976).

That, in our patients, toxic serum levels of phenytoin correlated with many abnormalities in the EEG may be noteworthy. Also, selective morphological changes in the cerebellum have been attributed to the long-term administration of phenytoin-for example, Ghatak et al. (1976). We must be careful in assigning a cause and effect relationship to phenytoin administration. However, the EEG abnormalities of our patients with phenytoin might in part be attributed to this treatment. Previous results in this same series of patients showed that the degree of cerebellar atrophy correlated better with serum phenytoin concentrations than with the severity of epilepsy (Iivanainen et al., 1977).

In patients who had frequent seizures, it was not possible to say which seizures were caused by the disease and which, if any, were brought on by phenytoin. Before any interrelationships among EEG abnormalities, serum phenytoin levels, and the severity of epilepsy can be established with certainty, prospective studies are needed in which serum phenytoin concentrations are monitored, the severity of epilepsy is determined as precisely as possible, and EEG abnormalities are identified before the medication and continuously assessed thereafter.

Demonstration of the importance of this last factor was a clear result of the present studynamely, that the continuous EEG monitoring of the effects of antiepileptic drugs is not only a useful but an essential adjunct to the successful treatment of severe epilepsy (cf. Porter et al., 1977).

This research was supported in part by the National Welfare Association for the Mentally Deficient in Finland (Kehitysvammaliitto ry) anl the Rinnekoti Foundation.

\section{References}

Ahmad, S., Laidlaw, J., Houghton, G. W., and Richens, A. (1975). Involuntary movements caused by phenytoin intoxication in epileptic patients. Journal of Neurology, Neurosurgery, and Psychiatry, 38, 225-231.

Bente, D. (1975). Antikonvulsiva und Elektroenzephalogramm. Bibliotheca Psychiatrica, 151, 182-189.

Buchthal, F., Svensmark, O., and Schiller, P. J. (1960). Clinical and electroencephalographic correlations with serum levels of diphenylhydantoin. Archives of Neurology (Chicago), 2, 624-630.

Dow, W. I. M. (1971). Electroencephalogram in anticonvulsant-induced folate deficiency. British Medical
Journal, 2, 207.

Dumermuth, G. (1965). Elektoencephalographie im Kindesalter. Einführung und Atlas. Georg Thieme Verlag: Stuttgart.

Fink, M. (1969). EEG and human psychopharmacology. Annual Review of Pharmacology, 9, 241-256.

Ghatak, N .R., Santoso, R. A., and McKinney, W. M. (1976). Cerebellar degeneration following long-term phenytoin therapy. Neurology (Minneapolis), 26, 818-820.

Gibbs, F. A., and Gibbs, E. L. (1965). The electroencephalogram in mental retardation. In Medical A spects of Mental Retardation, pp. 112-125. Edited by C. H. Carter. Charles C. Thomas: Springfield Illinois.

Iivanainen, M. (1974). A Study of the Origins of Mental Retardation. Clinics in Developmental Medicine No. 51. Spastics International Medical Publications in association with William Heinemann Medical Books Ltd: London, and J. B. Lippincott: Philadelphia.

Iivanainen, M., and Viukari, M. (1977). Serumphenytoin, seizures and electroencephalography. Lancet, 1, 860-861.

Iivanainen, M., Viukari, M. and Helle, E.-P. (1977). Cerebellar atrophy in phenytoin-treated mentally retarded epileptics. Epilepsia (New York), 18, 375386.

Jensen, B. N., and Grynderup, V. (1966). Studies on the metabolism of phenytoin. Epilepsia (Amsterdam), 7, 238-245.

Lambie, D. G., Johnson, R. H., Nanda, R. N., and Shakir, R. A. (1976). Therapeutic and pharmacokinetic effects of increasing phenytoin in chronic epileptics on multiple drug therapy. Lancet, 1, 386389.

Levy, L. L., and Fenichel, G. M. (1965). Diphenylhydantoin activated seizures. Neurology (Minneapolis), 15, 716-722.

Le Quesne, P. M., Goldberg, V., and Vajda, F. (1976). Acute conduction velocity changes in guinea-pigs after administration of diphenylhydantoin. Journal of Neurology, Neurosurgery, and Psychiatry, 39, 995-1000.

Logan, W. J., and Freeman, J. M. (1969). Pseudodegenerative disease due to diphenylhydantoin intoxication. Archives of Neurology (Chicago), 21, 631-637.

McLellan, D. L., and Swash, M. (1974). Choreoathetosis and encephalopathy induced by phenytoin. British Medical Journal, 2, 204-205.

Morrell, F., Bradley, W., and Ptashne, M. (1959). Effect of drugs on discharge characteristics of chronic epileptogenic lesions. Neurology (Minneapolis), 9, 492-498.

Müller, J., and Müller, D. (1972). Hirnelektrische Korrelate bei Überdosierung von antikonvulsiven Medikamenten. Nervenarzt, 43, 270-272.

Perucca, E. (1976). A study of intoxication with antiepileptic drugs among a large in-patient population. VIIth International Symposium on Clinical Pharmacology, Pavia, Italy. 
Porter, R. J., Penry, J. K., and Lacy, J. R. (1977). Diagnostic and therapeutic reevaluation of patients with intractable epilepsy. Neurology (Minneapolis), 27, 1006-1011.

Roseman, E. (1961). Dilantin toxicity. A clinical and electroencephalographic study. Neurology (Minneapolis), 11, 912-921.

Stensrud, P. A., and Palmer, H. (1964). Serum pheny- toin determinations in epileptics. Epilepsia (Amsterdam), 5, 364-370.

Viukari, N. M. A. (1970). Diphenylhydantoin in the treatment of mentally subnormal epileptics, concentrations of diphenylhydantoin in serum and cerebrospinal fluid and the main electrolytes. Thesis, Helsinki. 